\title{
Agricultural business economics: the challenge of sustainability
}

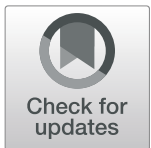

\author{
Giulio Malorgio ${ }^{1 *}$ and Francesco Marangon ${ }^{2}$
}

\author{
* Correspondence: giulio.malorgio@ \\ unibo.it \\ ${ }^{1}$ Department of Agricultural and \\ Food Sciences, University of \\ Bologna, Bologna, Italy \\ Full list of author information is \\ available at the end of the article
}

The agri-food sector is facing new and important challenges. These challenges are the consequence of the profound changes that have recently affected the national and international economic scenario.

In this context, new frontiers of research and investigation seem to have recently opened. On the one hand, these new frontiers derive from previous unresolved issues; on the other hand, they derive from the growing awareness that natural resources are becoming more and more limited and threatened by short-sighted choices. These issues have been recently addressed in the document of the EU Commission on the Green Deal, which highlights how, in light of new challenges, a new growth strategy is necessary (European Commission 2019):

"That will transform the Union into a modern, resource-efficient and competitive economy, where there are no net emissions of greenhouse gases by 2050, economic growth is decoupled from resource use, and no person and no place are left behind"

Within this program, agriculture plays a significant role that has a relevant impact on the environment. Its performance can be measured not only from a socio-economic point of view, but also from an ethical and even from an aesthetical one, given the impact it has on the landscape. In other words, the relationship between agriculture, environment, and society is intensified and diversified. Here, a new paradigm is expected, placing on the one hand agricultural farms in front of an ecological transition while on the other in front of an ethical-social change.

The European Green Deal takes its first implementation steps to revolutionize the European economy and society in a "green" sense and to achieve the goal of mitigating the effects of climate change. Among the programs launched by the commission aimed at mobilizing research and innovation to promote a just and sustainable society transition, we can highlight the following: "Farm to fork" (European Commission 2020), "EU Biodiversity Strategy for 2030 Bringing nature back into our lives," and "Stepping up Europe's 2030 climate ambition, investing in a climate-neutral future for the benefit of our people". These programs have complementary strategies and intend to push the whole economy towards innovative and virtuous systems with zero climate impact.

(c) The Author(s). 2021 Open Access This article is licensed under a Creative Commons Attribution 4.0 International License, which permits use, sharing, adaptation, distribution and reproduction in any medium or format, as long as you give appropriate credit to the original author(s) and the source, provide a link to the Creative Commons licence, and indicate if changes were made. The images or other third party material in this article are included in the article's Creative Commons licence, unless indicated otherwise in a credit line to the material. If material is not included in the article's Creative Commons licence and your intended use is not permitted by statutory regulation or exceeds the permitted use, you will need to obtain permission directly from the copyright holder. To view a copy of this licence, visit http://creativecommons.org/licenses/by/4.0/. 
Particularly, agriculture is involved in a set of objectives to be achieved by 2030 in a very significant (and not riskless) way: a 50\% reduction in pesticides, $20 \%$ reduction in fertilizers, 50\% reduction in the sales of antimicrobials for livestock and aquaculture, achievement of at least $25 \%$ of the agricultural area with organic farming, transformation of at least $10 \%$ of agricultural land into areas with high biodiversity, and protection of at least $30 \%$ of rural and marine areas.

These objectives will require the operational, but also financial, involvement of agricultural enterprises to adapt to new requirements of the production and to seek innovative solutions (Matthews 2020). This will aim at not only achieving the objectives set by the EU Commission, but also maintaining an adequate level of competitiveness in the domestic and foreign market. The risk of a quantitative decrease in agricultural production with harmful consequences for producers should be avoided, as well as the shift of the demand from domestic high-added-value products to extra-European cheaper with lower health and environmental standards. The perspective of sustainable intensification should, therefore, be the one to pursue. Intensifying also means to embody more knowledge and the right technology into the production process in order to combine an intensive and productive agriculture with high standards of agriculturalbased environmental "performances" (Buckwell et al. 2014).

Today more than ever before, agricultural and food enterprises are involved in processes of transformation of the production system, within which they have the task of developing a strategy that maintains unaltered the economic vitality and improves the environmental and social sustainability. It is therefore not only a question of producing quality goods with a good level of differentiation on national and international markets, but also of providing public goods. It entails also of developing organizational and technological knowledge that guarantees an effective relationship with partners of the supply chain as well strategy adopting sustainable production techniques for the protection of the environment, the rational use of natural resources, the protection of biodiversity, and the enhancement of local resources.

All these leads to a significant increase in the complexity of the strategies and functions that agri-food enterprises are required to perform, subjected to many complex technical and socio-environmental constrains which agri-food enterprises have to deal in order to maintain and improve their economic vitality and efficiency.

In this scenario, agricultural economists are increasingly sked to concentrate their attention and their skills on the study of agricultural business economy, as well as on the different organizational and management forms along the supply chain, to contribute to defining and motivating sustainable development and transformation paths suited to present and future scenarios. This pens up new applied and methodological research frontiers in the field of business economics. In this regard, agricultural economists are encouraged to explore innovative study paths and to brush up on some tools, left out due to academic needs and opportunities, overcoming the basic assumptions of neoclassical theory. For instance, the neo-institutionalist theory, in the study on vertical relations of the food chain, or from a methodological point of view, industrial organization models to analyze strategic behavior and interactions of companies in vertical chains and to assess the impacts of various forms of contract.

The new agricultural business economics can benefit from emerging approaches such as the Bioeconomy and One Health. The Bioeconomy approach (Viaggi 2018), based 
on the efficient use of natural and biological resources, brings together different areas of industrial science and technology, and is characterized by an integrated multidimensional approach. To illustrate, the bioeconomic approach seek to simultaneously achieve the following goals: efficient resource management, protection of biodiversity, soil conservation, production of ecological and social services, valorization of waste and by-products, and production of bioenergy through the efficient and sustainable use of renewable resources.

From this perspective, the bioeconomy is increasingly connected and functional to the public choice sector which regulates innovation, production processes, and the allocation of property rights. Moreover, the economic theory of property rights, which identify the conditions to achieve a long-term sustainable resource "community" management, through the assessment of marketable and non-marketable aspects and common goods, is still today seen as a test for agricultural economic research. For instance, ecosystem services generated by the agricultural sector and natural coastal environments show the multifunctional role of the primary sector, contributing to social and environmental equilibria and, therefore, worthy of attention in the definition of economic policies.

A rather overlooked but emerging topic due to the recent health crises (Belik 2020) is that of One Health approach, a multidisciplinary approach with a systemic vision of the business economy to manage and respond effectively to the foodborne diseases along the food chain.

Food is an important aspect of health, not only from a nutritional point of view, but also because it carries pathologies (foodborne diseases) that are transmitted through the production processes and the supply chain. Quality is called into question, not only as we usually consider it (brands, origin, etc...), but as a broader health-based concept, which brings together production methods, animal health, and eating habits. Animal production is a central aspect in this context. The health costs that are faced upstream and along the supply chain are a safety issue for the consumer, and its absence would generate costs for individuals and for the system as a whole (in this case the public health).

For the future of agricultural economics research, behavioral economics tools deserve to be mentioned. These tools are aimed at analyzing the decision-making processes of farmers and consumers in front of new sets of options coming from new technological solutions, European policies, novel foods, and objectives of a different nature (economic, environmental, social). The speed of adoption of new technologies, the attitude to risk, the propensity to collaborate, and time preferences are all dimensions that can be analyzed from the perspective of behavioral economics.

Other indications may come from tools linked to the economy of innovation in which factors such as digitization and information technology are integrated into the process of business economic choices, between product and means, as well as between product and product, and between means of production, to define new performing business models.

Today's innovation, while maintaining a decisive role in the technological progress of the agricultural and food sector, has a different meaning than in the past. It is no longer considered only a component to increase the productivity of the means of production, but it has the task of organizing production systems and combining the factors of production of new technical and economic trajectories, that means pursuing different performance criteria based on sustainability parameters in its various dimensions. 
Finally, we must not forget some territorial approaches, in large part already addressed by agricultural economists, but which should be taken up in a specific and in-depth analysis. These approaches should be re-explored and interpreted not only with a productivist view, but also with a view of socio-economic and environmental balance, highlighting the pluralism of development of territorial agricultural systems and local models.

Therefore, the agri-food enterprise, as an institution operating in a highly integrated scenario and with direct responsibility towards the surrounding environment, acquires a strengthened role in building a more sustainable, fair, and competitive system and relaunching and preserving biodiversity. Incorporating the concept of sustainability in the food production and consumption will benefit all players in the food chain, especially farmers. For too long, the agricultural enterprise has been considered exclusively having a passive role, as an instrument on which to operate through various political interventions according to specific objectives (productivism, food security, environmental and territorial changes, local development, etc...), or as an actor at the mercy of the market, customers, international competition, and changing consumers' choices. It is perhaps time to rediscover the active role of the agricultural enterprise, highlighting the importance of the difficult business choices that are made under the stimulus of various constraints and objectives, in a climate of uncertainty and in comparison, with the actions of other actors of the economic system. Perhaps, it should be clarified that, in the midst of different obstacles, guided paths, more or less blocked roads, and decision-making labyrinths, we are still dealing with autonomous and independent choices, and not inevitable reactions to a deterministic world. In this context, agricultural economists must return to pay more attention to the study and analysis of business economy to seize the challenges and opportunities dictated by the new course of agri-food development in the near future.

Authors' contributions

The author(s) read and approved the final manuscript.

Competing interests

The authors declare that they have no conflict of interests.

Author details

${ }^{1}$ Department of Agricultural and Food Sciences, University of Bologna, Bologna, Italy. ${ }^{2}$ Department of Economics and Statistics, University of Udine, Udine, Italy.

Published online: 21 January 2021

References

Belik W (2020) Sustainability and food security after COVID-19: relocalizing food systems? Agric Econ 8:23. https://doi.org/10. 1186/s40100-020-00167-z

Buckwell A, Heissenhuber A, Blum W (2014) Sustainable Intensification of European Agriculture. RISE Foundation, Brussels https://risefoundation.eu/wp-content/uploads/2020/07/2014_-SI_RISE_FULL_EN.pdf

European Commission (2019), The European Green Deal, Communication from the Commission to the European Parliament, the European Council, the Council, the European Economic And Social Committee and the Committee of the Regions, $\operatorname{COM}(2019) 640$ final, https://eur-lex.europa.eu/legal-content/EN/TXT/?uri=CELEX\%3A52019DC0640

European Commission (2020), Farm to Fork Strategy for a fair, healthy and environmentally-friendly food system, Communication from the Commission to the European Parliament, the European Council, the Council, the European Economic And Social Committee and the Committee of the Regions, COM/2020/381 final, https://eur-lex.europa.eu/legalcontent/EN/TXT/?qid=1590404602495\&uri=CELEX\%3A52020DC0381

Matthews A (2020) The new CAP must be linked more closely to the UN Sustainable Development Goals. Agric Econ 8:19. https://doi.org/10.1186/s40100-020-00163-3

Viaggi D (2018) The bioeconomy: delivering sustainable green growth. CABI Publishing, Boston

\section{Publisher's Note}

Springer Nature remains neutral with regard to jurisdictional claims in published maps and institutional affiliations. 